\title{
Intoxicação por agrotóxicos agrícolas no estado de Goiás, Brasil, de 2005-2015: análise dos registros nos sistemas oficiais de informação
}

\author{
Poisoning by agricultural pesticides in the state of Goiás, Brazil, \\ 2005-2015: analysis of records in official information systems
}

Pedro Dias Mangolini Neves (https://orcid.org/0000-0002-3869-1367) ${ }^{1}$

Marcelo Rodrigues Mendonça (https://orcid.org/0000-0003-1653-0965) ${ }^{1}$

Marcella Bellini (https://orcid.org/0000-0003-1984-7757) ${ }^{2}$

Isabela Braichi Pôssas (https://orcid.org/0000-0001-6904-9898) ${ }^{3}$
${ }^{1}$ Instituto de Estudos Socioambientais, Universidade Federal de Goiás. Av. Dr. Lamartine Pinto de Avelar 1120, Setor Universitário. 75700000 Catalão GO Brasil. pmangolini@hotmail.com ${ }^{2}$ Programa de Pós-

Graduação em Psicologia, Universidade Federal do

Triângulo Mineiro. Uberaba MG Brasil.

3 Programa de Pós-

Graduação em Geografia,

Universidade Estadual

Paulista Júlio de Mesquita

Filho Rio Claro SP Brasil.
Abstract The effect of pesticide use on human health is a problem that has received attention from the scientific community worldwide, especially in central countries, where the highest number of deaths due to human exposure to these agents is observed. Production and productivity increased through the progress of agro-industrialization, but risks to the environment and health were not taken into account. Over time, several cases of environmental contamination and public health problems, poisoning of rural workers, and food residues were observed. These factors triggered the recognition of risks arising from pesticide abuse. This study aimed to characterize pesticide poisonings reported to a toxicological information center of the state of Goiás through a retrospective analysis from 2005 to 2015. Data were mapped and tabulated by the purpose of pesticides, the circumstance of poisoning, and case development. The poisoning profile pointed to a higher occurrence of work- and suicide-related poisonings, with a predominance of poisoned patients, although chronic effects were not recorded, suggesting a false diagnosis of cure.

Key words Poisoning, Agrochemicals, Geographic mapping, Information systems, Compulsory notification
Resumo Os efeitos do uso de agrotóxicos sobre a saúde humana é um problema que tem merecido atenção da comunidade científica em todo o mundo, sobretudo nos países centrais, onde se observa o maior número de mortes decorrentes da exposição humana a esses agentes. Mediante o progresso da agroindustrialização, garantiu-se o aumento da produção e da produtividade, todavia, não se considerou os riscos ao ambiente e a saúde. Ao longo do tempo foram observados diversos casos de contaminação ambiental e de problemas de saúde pública, intoxicações de trabalhadores rurais e resíduos em alimentos. Esses fatores desencadearam o reconhecimento dos riscos decorrentes do uso abusivo dos agrotóxicos. O objetivo deste estudo foi caracterizar intoxicações por agrotóxicos reportadas a um centro de informação toxicológica de Goiás por meio de análise retrospectiva no período de 2005 a 2015. Os dados foram mapeados e tabulados segundo a finalidade dos agrotóxicos, a circunstância da intoxicação, e evolução do caso. O perfil das intoxicações apontou para ocorrência superior de intoxicações por tentativa de suicídio e ocupacional, com predominância de cura dos intoxicados apesar dos efeitos crônicos não serem registrados, sugerindo um falso diagnóstico de cura. Palavras-chave Envenenamento, Agroquímicos, Mapeamento geográfico, Sistemas de informação, Notificação compulsória 


\section{Introdução}

Substâncias químicas com fins de controle de pragas e doenças têm registros entre os escritos gregos e romanos há mais de 3.000 anos $^{1}$. No Brasil, a introdução dos agrotóxicos foi feita de forma organizada, acompanhada de pacotes tecnológicos que introduzia a mecanização em larga escala, associada a outros fatores de produção por meio de gastos pré-estabelecidos de financiamentos estatais ( $30 \%$ do financiamento deveria ser gasto em inseticidas e $20 \%$ em herbicidas). Neste contexto, o objetivo foi incentivar a modernização do território, mediante a modernização do campo (agroindustrialização), para garantir o aumento da produção e da produtividade, sem considerar riscos ao ambiente e a saúde.

Ao longo do tempo foram observados diversos casos de contaminação ambiental e de problemas de saúde pública, intoxicações de trabalhadores rurais e resíduos em alimentos. Esses fatores desencadearam o reconhecimento dos riscos decorrentes do uso abusivo dos agrotóxi$\cos ^{1-6}$. Os efeitos do uso de agrotóxicos sobre a saúde humana é um problema que tem merecido atenção da comunidade científica em todo o mundo, sobretudo, nos países emergentes, em que se observa o maior número de mortes decorrentes da exposição humana a esses agentes ${ }^{7}$, pois os pacotes tecnológicos continuam a serem impostos, sem considerar as condições edafoclimáticas, os processos históricos de usos do solo e da água e os saberes-fazeres das populações.

Segundo Alves Filho ${ }^{1}$ o aumento dos problemas relacionados aos agrotóxicos de uso agrícola levou à criação da Lei dos Agrotóxicos em 1989, pelo Ministério da Saúde (MS), Ministério da Agricultura, Pecuária e Abastecimento (MAPA) e pelo Instituto Brasileiro do Meio Ambiente e dos Recursos Naturais Renováveis (IBAMA). Antes disso (1980) houve a criação do Sistema Nacional de Informações Farmaco-Toxicológicas (SINITOX) servindo como um banco de dados de diferentes intoxicações. E em 1996 houve a inclusão da Ficha de Notificação por agrotóxico no Sistema de Informações de Agravos de Notificações (SINAN), mesclando a notificação e o atendimento junto ao sistema de controle de informações toxicológicas para a investigação dos acidentes com agrotóxicos. Esse monitoramento tem como objetivo expor a situação das intoxicações por agrotóxicos e delimitar campos de atuação, a fim de reduzir o número de acidentes ${ }^{8}$.

A Agência Nacional de Vigilância Sanitária (ANVISA) ${ }^{9}$ identificou que a taxa de crescimento do mercado brasileiro de agrotóxicos no período de dez anos (2000 a 2010) foi de 190\%, enquanto no mercado mundial foi de $93 \%$ nesse mesmo período.

Se por um lado tem-se a percepção de eficiência agronômica dos agrotóxicos, já que, uma vez que o usuário consegue observá-la na lavoura ou no ambiente urbano onde houve aplicação do composto químico e verificar sua ação esperada e descrita nos rótulos, por outro, tem-se o problema relacionado ao risco que tais produtos acarretam à saúde dos seres humanos e o impacto/destruição que provocam no ambiente. A ação dos agrotóxicos geralmente não consegue ser seletiva a ponto de extirpar apenas o que se pretende e, na maioria das vezes, o extermínio se dá em várias outras classes de componentes da fauna e da flora existentes no local da aplicação ${ }^{10}$.

De acordo com estudos de Nishiyama ${ }^{11}$, devido à sua alta atividade biológica e à sua persistência no ambiente, os agrotóxicos podem causar efeitos indesejáveis à saúde e a natureza. Seu manuseio inadequado pode resultar em intoxicações agudas e, às vezes, em efeitos de longo prazo (intoxicações crônicas) causados pela exposição a agrotóxicos.

Neste sentido, há tempos discute-se sobre a diminuição das abelhas, devido ao uso intenso de agrotóxico e suas consequências para a reprodução das flores, pois são as abelhas que auxiliam no processo de polinização, impactando diretamente aspectos da reprodução das flores ${ }^{10}$. Em relação aos efeitos destes produtos na saúde humana, o Professor Wanderlei Pignati (UFMT), juntamente com Jorge Machado e James Cabral, ao estudarem o Município de Lucas do Rio Verde/MT, constataram índices alarmantes de contaminação por agrotóxico, atingindo inclusive o leite materno das mulheres do município, ressaltando que nenhuma delas atuava diretamente na agricultura $^{12}$.

Em algumas pesquisas são relatados a não utilização dos Equipamentos de Proteção Individual (EPI) pelos agricultores, como em Nova Friburgo/RJ ${ }^{13}$, demostrando que cerca de $70 \%$ dos entrevistados não fazem uso destes equipamentos, facilitando ainda mais a intoxicação destes agricultores/trabalhadores. É importante ressaltar que os EPI não são equipamentos confortáveis, são quentes (e seu uso majoritariamente realizado em ambiente externo sujeito a radiação solar, portanto quente) e de não maleáveis, dificultando as atividades manuais (com a mão), por isso há uma resistência e rejeição em sua utilização por estes sujeitos. 
Ao contrário do que acontece com as intoxicações agudas, é muito difícil estabelecer as relações de causa e efeito para os envenenamentos crônicos, isto é, para as manifestações mórbidas que surgem meses ou anos após a exposição continuada e frequente a pequenas doses de pesticidas. A situação torna-se ainda mais complexa pelo grande número de marcas comerciais com distintos princípios ativos, que não são de conhecimento habitual dos médicos. Nestes casos é indispensável que o médico possa contar com os serviços de um Centro de Informação Toxicológica (CIT), que responda com rapidez sobre a composição química de um produto incriminado como responsável pelo caso e forneça especificações para diagnóstico, indicações sobre antídotos ou outros medicamentos e prognóstico.

No estado de Goiás, o CIT-GO, está localizado na Superintendência de Vigilância Sanitária em Saúde (SUVISA) e foi fundado em 1986, a partir da necessidade de ter um serviço especializado capaz de prestar informações relacionadas a agentes tóxicos existentes no meio. O Plantão de Atendimento do CIT-GO promove um direcionamento resolutivo ao atendimento do paciente, diminuindo com isso sua vulnerabilidade e a fragilidade do sistema de saúde frente aos casos suspeitos de intoxicação, porém falta articular melhor os pontos da rede de atenção à saúde com encaminhamentos à serviços de saúde mental e serviço social, por exemplo, quando a intoxicação é por tentativa de suicídio ou contaminação infantil, haja vista que hoje em dia o protocolo de conduta clínica prevê o pós-atendimento apenas por meio de ligações telefônicas para averiguar o quadro evolutivo do intoxicado, a posologia e os efeitos das medicações prescritas, até a melhora do quadro clínico do sujeito.

Os registros de intoxicações do CIT-GO, localizado na SUVISA, em Goiânia/GO, são repassados por meio de planilhas eletrônicas para o SINITOX, e este faz o trabalho de armazenamento e disponibilização das informações em anuário. Os municípios também repassam as fichas de notificações para o CIT-GO e ficam responsáveis em disponibilizar tais informações de intoxicações para o SINITOX, mas geralmente estas fichas demoram a ser repassadas ou às vezes não são digitalizadas, pela estrutura precária dos municípios, pela falta de funcionários e principalmente falta de interesse político, uma vez que, a maioria, são hegemonizados pelo agronegócio.

Isto posto, percebe-se que a melhor forma de se analisar as intoxicações de um estado ou municípios inseridos nesta unidade federativa, é buscar as fichas de notificação de intoxicação armazenadas nos Centro de Informações Toxicológicas instalados nas Superintendências de Vigilância Sanitária de cada unidade federativa do país, como o SINITOX orienta em seu próprio site, além disso, o SINAN. Como o SINITOX, o SINAN é alimentado, principalmente, pelas Secretarias municipais de saúde. E como também orienta na sua página eletrônica, que a Ficha Individual de Notificação (FIN) deve ser preenchida pelas unidades assistenciais para cada paciente quando da suspeita da ocorrência de problema de saúde de notificação compulsória ou de interesse nacional, estadual ou municipal.

Notadamente estes serviços são excelentes sistemas de notificações de agravos à saúde da população brasileira, todavia, são alimentados por secretarias municiais e/ou estaduais, por profissionais sobrecarregados com diversas outras funções que não conseguem alimentar o banco de dados com a agilidade necessária, tendo em vista que os dados do SINITOX e do SINAN nem sempre estão atualizados ao ano vigente.

Tal fato torna-se importante para compreendermos os motivos que levam às subnotificações nos casos de contaminação por agrotóxicos, uma vez que o número que apresentaremos de intoxicação tende a ser muito maior, considerando informações do Conselho Nacional de Secretarias de $S_{a u ́ d e}{ }^{14}$, a subnotificação nestes casos é da ordem de 1 para 50 , ou seja, para cada caso notificado há 50 não notificados, mesmo assim, os dados disponíveis são alarmantes.

Neste ínterim, como metodologia, foi realizada uma coleta de dados por meio de visitas técnicas a Biblioteca do CIT-GO, com acesso permitido após aprovação do Secretário de Saúde do estado de Goiás. As fichas de notificações de intoxicações exógenas de uso agrícola de 2005 a 2015 foram catalogadas ressalta-se que as fichas dos anos de 2016 e 2017 ainda não estavam disponíveis por procedimentos operacionais de recebimento e tratamento das queixas e/ou denúncias.

Todas as fichas disponíveis foram tabuladas a partir dos dados existentes como por exemplo, municípios e mês em que houve a intoxicação, tipo de agente intoxicante, circunstância e agrotóxico que ocasionou a intoxicação e evolução do caso. A partir destes dados sistematizados, a segunda etapa consistiu em elaborar mapas de distribuição dos casos de intoxicação e produção agrícola, tomando como base o Sistema Estadual de Geoinformação de Goiás (SIEG) e shapefiles. O software utilizado na elaboração dos mapas foi o ArcGis, permitindo a espacialização e distribui- 
ção dos casos de intoxicação por agrotóxicos de uso agrícola no estado de Goiás.

Ressaltamos também a importância dos trabalhos de Larissa Mies Bombardi em "Pequeno Ensaio Cartográfico sore o Uso de Agrotóxicos no Brasil"15 e em "Geografia do Uso de Agrotóxicos no Brasil e Conexões com a União Europeia"16 na espacialização e discussão sobre agrotóxicos no Brasil.

\section{Mapa de intoxicações por agrotóxicos agrícolas no estado de Goiás (2005 a 2015)}

Com a coleta de dados realizada junto à Biblioteca do CIT-GO através de fichas de notificações de intoxicações exógenas de uso agrícola de 2005 a 2015 foi possível desenvolver o Mapa de Intoxicações por Agrotóxicos de uso agrícola em Goiás, de 2005 a 2015 (Figura 1).

A partir deste mapa foi possível identificar quais as regiões do estado apresentam uma concentração maior de casos de intoxicação, buscando compreender os fenômenos por detrás dos discursos e ações que tornaram Goiás o celeiro agrícola brasileiro. Destaca que o maior número de notificações de intoxicação por agrotóxicos nas áreas territorializadas pelo agronegócio, sendo possível fazer a relação agronegócio/agrotóxicos, que pela quantidade de pesticidas empregada nas grandes lavouras de commodities, faz com que estas áreas sejam campeãs de malefícios ao ambiente e aos seres vivos.

Foram notificadas 2.987 intoxicações com a incidência maior em alguns municípios, como é o caso de Jataí/GO (304 intoxicações), Goiânia/ GO (249), Rio Verde/GO (157), Anápolis/GO (155), Formosa/GO (114), Acreúna/GO (106), Goiatuba/GO (104), Aparecida de Goiânia/GO (64), Mineiros/GO (56) e Montividiu/GO (46).

É necessário considerar que estes dados podem estar camuflados, pois o tamanho da população de um município pode interferir na quantidade de intoxicações. Deste modo, fazendo a relação entre o número de notificação de intoxicações pela estimativa populacional dos municípios, de acordo com o IBGE ${ }^{17}$, temos as informações contidas na Tabela 1.

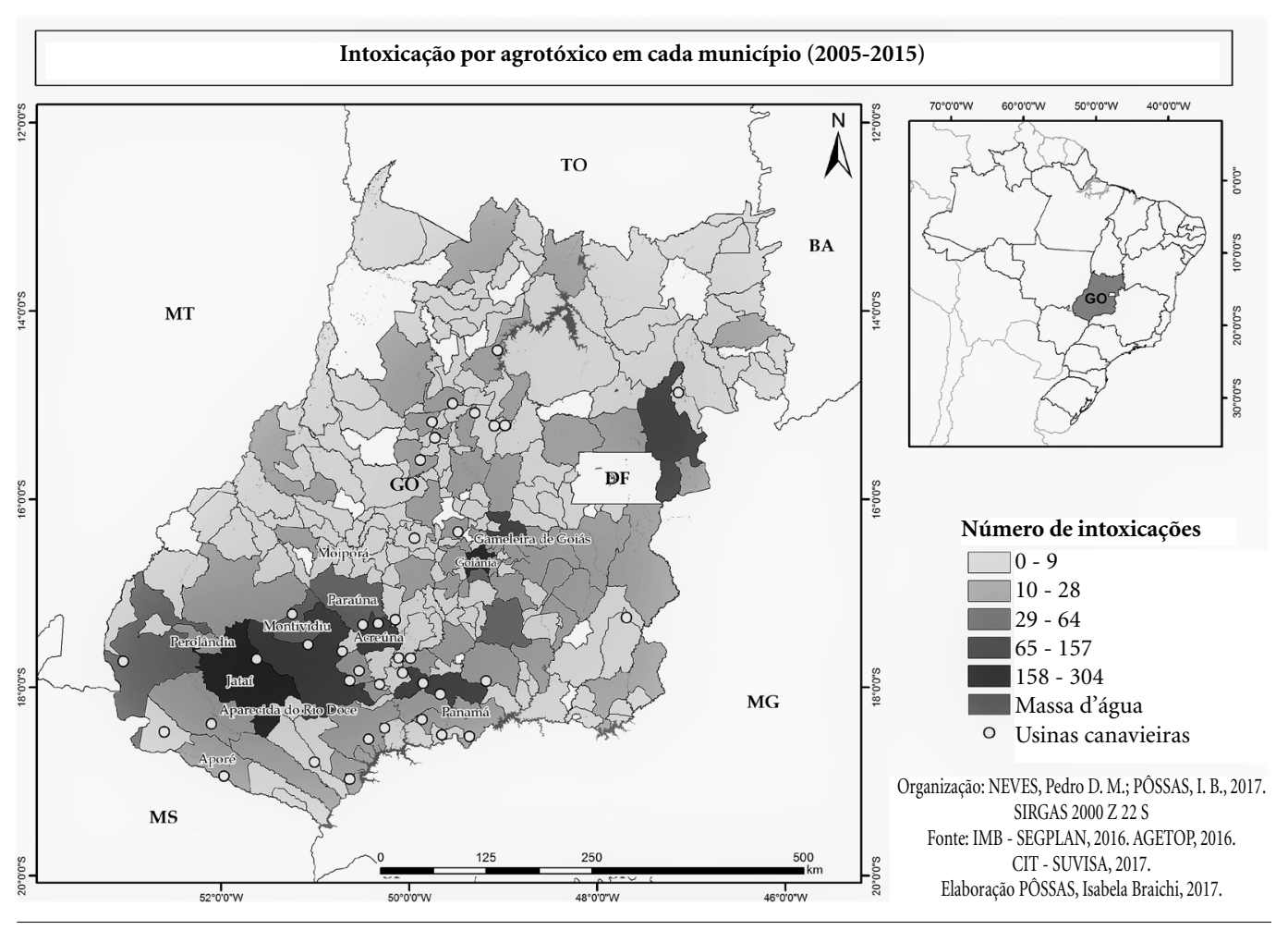

Figura 1. Mapa de intoxicação por agrotóxico de uso agrícola no estado de Goiás (2005-2015). 
Tabela 1. Relação do número de notificação de intoxicações pela estimativa populacional dos municípios (2015) mais intoxicados de Goiás.

\begin{tabular}{|c|c|c|c|c|c|c|c|}
\hline Município & Intoxicações & Habitantes & $\begin{array}{l}\text { Relação } \\
\text { Int./hab }\end{array}$ & Município & Intoxicações & Habitantes & $\begin{array}{l}\text { Relação } \\
\text { Int./hab }\end{array}$ \\
\hline Aporé & 25 & 4110 & 164,4 & Nerópolis & 17 & 27812 & 1636,0 \\
\hline Acreúna & 106 & 21905 & 206,6 & Iporá & 19 & 32218 & 1695,7 \\
\hline Montividiu & 46 & 12337 & 268,2 & Morrinhos & 25 & 45000 & 1800,0 \\
\hline Jataí & 304 & 97077 & 319,3 & $\begin{array}{l}\text { Santa Helena } \\
\text { de Goiás }\end{array}$ & 21 & 38563 & 1836,3 \\
\hline Goiatuba & 104 & 34179 & 328,6 & Inhumas & 28 & 51932 & 1854,7 \\
\hline Paraúna & 34 & 11210 & 329,7 & $\begin{array}{l}\text { São Luiz de } \\
\text { Montes Belos }\end{array}$ & 17 & 32808 & 1929,9 \\
\hline $\begin{array}{l}\text { Leopoldo de } \\
\text { Bulhões }\end{array}$ & 17 & 7758 & 456,3 & Cristalina & 28 & 54337 & 1940,6 \\
\hline Goianápolis & 23 & 11460 & 498,3 & Goianira & 19 & 40338 & 2123,0 \\
\hline Maurilândia & 23 & 13170 & 572,6 & Posse & 16 & 35128 & 2195,5 \\
\hline Barro Alto & 17 & 10235 & 602,0 & Porangatu & 20 & 45055 & 2252,7 \\
\hline Piracanjuba & 39 & 24830 & 636,7 & Anápolis & 155 & 370875 & 2392,7 \\
\hline Pontalina & 19 & 17933 & 943,8 & Quirinópolis & 16 & 47950 & 2996,9 \\
\hline Formosa & 114 & 114036 & 1000,3 & Caldas Novas & 26 & 83220 & 3200,8 \\
\hline Ceres & 22 & 22035 & 1001,6 & Goianésia & 16 & 66649 & 4165,6 \\
\hline Mineiros & 56 & 61623 & 1100,4 & Itumbiara & 21 & 101544 & 4835,4 \\
\hline Minaçu & 28 & 30862 & 1102,2 & $\begin{array}{l}\text { Senador } \\
\text { Canedo }\end{array}$ & 18 & 102847 & 5713,7 \\
\hline $\begin{array}{l}\text { Bela Vista de } \\
\text { Goiás }\end{array}$ & 25 & 28077 & 1123,1 & Goiânia & 249 & 1448639 & 5817,8 \\
\hline Silvânia & 18 & 20357 & 1130,9 & Trindade & 22 & 140930 & 6405,9 \\
\hline São Simão & 16 & 19407 & 1212,9 & $\begin{array}{l}\text { Aparecida de } \\
\text { Goiânia }\end{array}$ & 64 & 532135 & 8314,6 \\
\hline Rio Verde & 157 & 212327 & 1352,4 & Luziânia & 18 & 196864 & 10936,9 \\
\hline
\end{tabular}

Com a Tabela 1 podemos entender que Goiânia/GO não é um dos municípios com maiores taxas de pessoas intoxicadas quando relacionada com a quantidade de habitantes. Dentre os municípios goianos com maior número de intoxicados temos Aporé/GO com 01 intoxicação para cada 163 habitantes, Acreúna/GO com 01 intoxicação para cada 205 habitantes, Montividiu/GO com 01 intoxicação para cada 263 habitantes, Jataí/ GO com 01 intoxicação para cada 3195 habitantes, Goiatuba/GO com 01 intoxicação para cada 328 habitantes e Paraúna/GO com 01 intoxicação para cada 329 habitantes.

Isto posto, a fim de evitar que os dados apresentados possam ser ocultados devido a desproporção, as informações contidas na Figura 2 referem-se aos casos de notificação de intoxicações por agrotóxico por habitante de cada município.
Observando a Figura 2, pode se inferir que a Microrregião Sudoeste Goiano é a que apresenta a maior quantidade de notificações de intoxicações por habitante, justificada pela grande incidência de monocultivos agrícolas como soja, milho e cana-de-açúcar, que juntos foram os três setores que mais consomem agrotóxicos no Brasil, com cerca de $65 \%$ dos agrotóxicos vendidos no país, segundo Theisen ${ }^{18}$ e SINDAG ${ }^{19}$.

\section{Tipos de agentes intoxicantes}

Os agrotóxicos podem ser classificados de diferentes formas, entre elas: em relação à praga que se deseja controlar (inseticidas, herbicidas, fungicidas, dentre outros), o grupo químico (organofosforados, carbamatos, organoclorados, piretóides, bipiridílicos, mercuriais, dentre outros), 


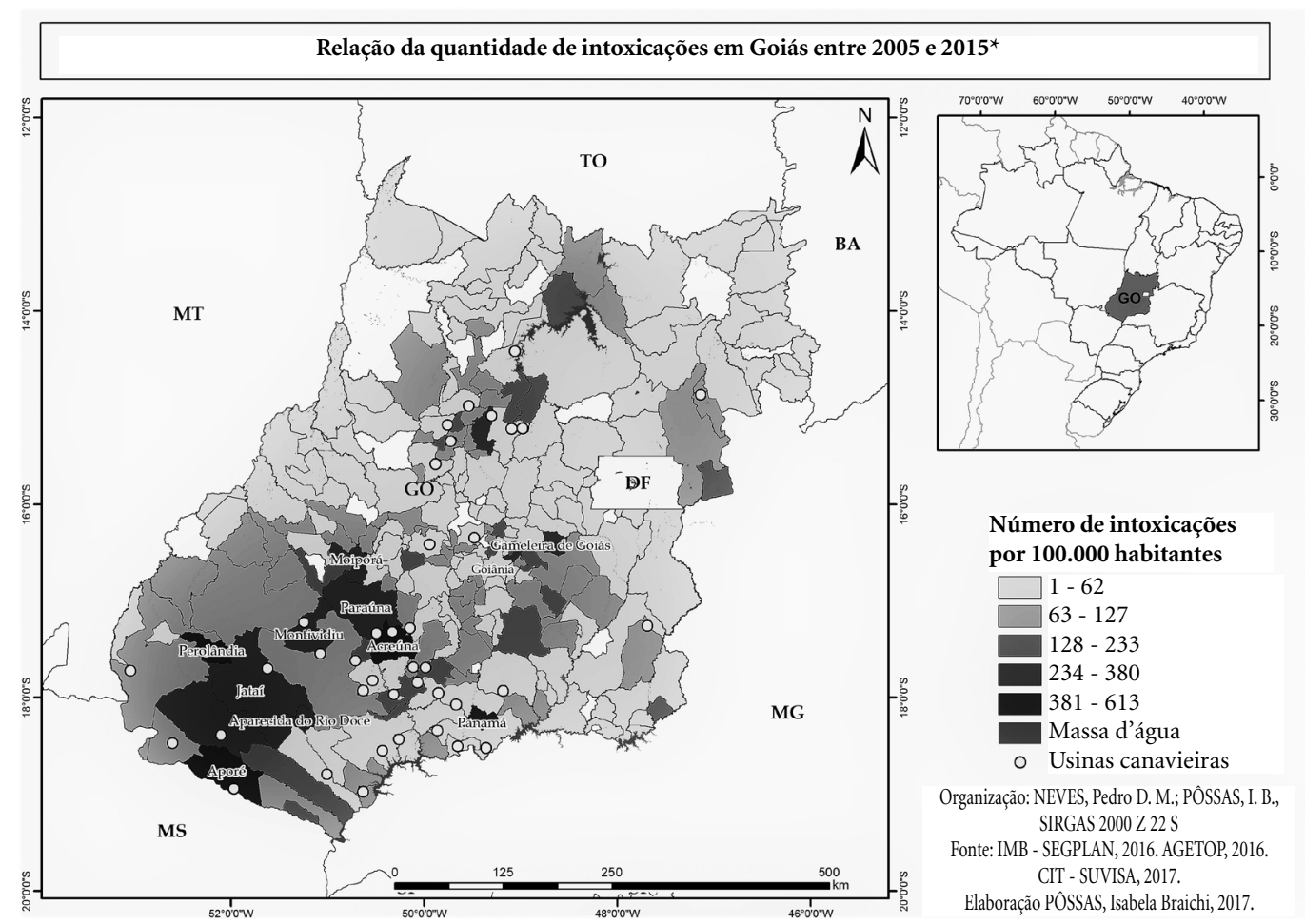

Figura 2. Mapa de notificação de intoxicação por agrotóxico de uso agrícola em relação ao número de habitantes no estado de Goiás (2005-2015).

Fonte: CIT/SUVISA (2016).

a toxicidade aguda (classe I, II, III, IV - de acordo com a DL50) e pela capacidade de provocar o desenvolvimento de câncer em seres humanos (carcinogênese). Neste sentido, de acordo com a classificação feita pela Agência Internacional de Pesquisa em Câncer (IARC) $)^{20}$, ligada à Organização Mundial da Saúde (OMS), diversas substâncias químicas, incluindo agrotóxicos, podem ser classificados em: 1 - Cancerígeno para humanos, 2A - Provavelmente cancerígenos para humanos, 2B - Possivelmente cancerígenos para humanos, 3 - Não classificável como cancerígeno para humanos, e 4 - Provavelmente não cancerígeno para humanos; e o tipo de formulação (solventes, aderentes, umectantes, etc) ou apresentação (líquido, pó ou granulado).

Os inseticidas são substâncias destinadas ao controle de insetos que causam danos as lavouras, ou fazem parte da cadeia epidemiológica de doenças infecto contagiosas. Já os herbicidas são substâncias destinadas ao controle de ervas da- ninhas que prejudicam o desenvolvimento das lavouras. E, finalmente, os fungicidas são substâncias destinadas ao combate de fungos que atacam, principalmente, as culturas de inverno ${ }^{21}$.

Na Tabela 2 podemos observar uma maior incidência de herbicidas e inseticidas utilizados em Goiás, e uma ocorrência mínima de fungicida.

Pode-se perceber que de 2005 a 2015 há um aumento no número de notificações por intoxicação por herbicidas e, consequentemente, acredita-se que houve uma maior utilização deste tipo de agrotóxico. De acordo com pesquisas disponíveis no "Dossiê ABRASCO: um alerta sobre os impactos dos agrotóxicos na saúde" ${ }^{21}$ a introdução de transgênicos nas lavouras brasileiras, alcançando cerca de $50 \%$ dos 74 milhões de hectares cultivados no Brasil ${ }^{22}$, que são tolerantes a herbicidas provocou um aumento do uso deste agrotóxico.

Segundo o mesmo Dossiê ABRASCO ${ }^{21}$, 93\% da área cultivada de milho, soja e algodão são de 
Tabela 2. Distribuição de pacientes intoxicados por agrotóxicos segundo a finalidade do agrotóxico em Goiás (2005-2015).

\begin{tabular}{lccccccc}
\hline \multicolumn{1}{c}{ Ano } & Inseticida & Herbicida & Formicida & Ignorado & Fungicida & Raticida & Carrapaticida \\
\hline 2005 & 112 & 61 & 76 & 51 & 6 & 8 & 4 \\
2006 & 84 & 75 & 53 & 43 & 3 & 2 & 7 \\
2007 & 57 & 63 & 47 & 10 & 6 & 2 & 3 \\
2008 & 72 & 77 & 43 & 45 & 7 & 2 & 1 \\
2009 & 65 & 90 & 34 & 45 & 15 & 3 & 6 \\
2010 & 62 & 87 & 48 & 73 & 18 & 0 & 3 \\
2011 & 48 & 70 & 30 & 50 & 19 & 1 & 1 \\
2012 & 82 & 142 & 29 & 34 & 5 & 0 & 0 \\
2013 & 130 & 147 & 25 & 31 & 9 & 1 & 2 \\
2014 & 86 & 150 & 30 & 52 & 16 & 2 & 0 \\
2015 & 64 & 112 & 16 & 23 & 11 & 0 & 0 \\
Total & 862 & 1074 & 431 & 457 & 115 & 21 & 27 \\
\hline
\end{tabular}

Fonte: CIT/ SUVISA (2016).

sementes transgênicas, já a cana-de-açúcar não possuía variedades transgênicas até 2016, porém, foi aprovado em junho pela Comissão Técnica Nacional de Biossegurança (CTNBio) o plantio de cana-de-açúcar transgênica. Dessa forma, a utilização e consequente intoxicação por herbicida tende a aumentar, necessitando de monitoramento e pesquisas mais aprofundadas.

Conforme as descrições nas fichas investigadas, é possível perceber que nestas notificações compulsórias há uma incidência de produtos que foram ignorados. Possivelmente, o preenchimento errôneo acontece pelo despreparo e falta de conhecimento dos profissionais que ocupam esta função, e ainda, o desconhecimento da população em relação aos produtos agrotóxicos que entram em contato diariamente. Isso exige, de imediato, capacitação dos servidores que lidam com a temática para que se atentem aos agravos à saúde ocasionados por estes produtos tóxicos, e com isso, possam recorrer às autoridades sanitárias a fim de que adotem medidas de intervenção adequadas. Por outro lado, deve-se valorizar maciças campanhas educativas para os consumidores e trabalhadores que manuseiam esses produtos, como por exemplo armazenamento, diluição do produto, manuseio, uso de equipamentos de proteção individual, entre outros.

Com os dados de notificações de intoxicações por agrotóxicos foi possível perceber o maior número de notificações em homens do que em mulheres (principalmente nas notificações ocupacionais), isto se deve principalmente ao fato de que a aplicação dos agrotóxicos é realizada, predominantemente, por trabalhadores do sexo masculino.

\section{Circunstância da intoxicação}

A exposição aos agrotóxicos pode ocorrer a partir do contato com a pele, mucosas, pela respiração ou ainda pela ingestão dos agrotóxicos ou de alimentos intoxicados, como diversos casos apresentados pelo Dossiê ABRASCO ${ }^{21}$ sobre os impactos dos agrotóxicos na saúde. A intoxicação pode acontecer de forma ocupacional, acidental ou intencional (tentativa de suicídio ou homicídio).

A exposição ocupacional refere-se a grupos profissionais que têm contato com agrotóxicos, pelos casos apresentados nas fichas de notificação de intoxicações no CIT-GO temos camponeses, funcionários de empresas rurais e até agentes de endemias, como os profissionais que trabalham com aspersão de veneno para o Aedes aegypti. Tal exposição pode ocorrer durante a diluição, a preparação da calda, a aplicação dos agrotóxicos e também devido a entrada nas lavouras após a aplicação dos produtos. Nas aplicações aéreas, os pilotos agrícolas e seus auxiliares também são considerados como grupo de risco.

Para Sobreira e Adissi ${ }^{3}$, uma das causas que contribuem para o aumento do número de casos de intoxicação é a utilização de agrotóxicos em larga escala, tendo como consequências um grande número de mortes e doenças dos trabalhadores, que inalam o produto, inadvertidamente, durante a aplicação ou através do contato com a pele. Assim, os agrotóxicos atingem tanto a natureza quanto as condições de saúde coletiva, já que resíduos de agrotóxicos podem ser ingeridos através de alimentos, devido ao fato destes compostos serem potencialmente tóxicos aos seres humanos. 
Pignati et al. ${ }^{23}$ em pesquisa sobre os impactos dos agrotóxicos na saúde, trabalho e ambiente para municípios brasileiros apresentou dados médios de utilização de agrotóxicos no estado de Mato Grosso de 10 litros por hectare. É este consumo exorbitante que faz com que o Brasil seja o campeão em consumo de agrotóxicos no mundo, consequentemente, gerando intoxicação no ambiente e na saúde da população.

$\mathrm{Na}$ exposição acidental estão os intoxicados que podem entrar em contato com os agrotóxicos em ambientes domésticos ao repelir insetos, quando as pessoas reutilizam o frasco do produto colocando algum outro material, ocasionando acidentes domésticos com a confusão de embalagens, principalmente por crianças e idosos.

Neste tipo de exposição há também o efeito de deriva, que é o transporte aéreo das partículas dos agrotóxicos para áreas que não sejam as áreas de aplicação destes, como as residências próximas as lavouras de cana-de-açúcar, soja ou milho.

Já na exposição intencional que nesta pesquisa está dividida em tentativa de suicídio e tentativa de homicídio, são intoxicações provocadas com intenção de tirar a própria vida, ou de outra pessoa. A intoxicação por tentativa de suicídio é a intoxicação que possui os maiores índices de letalidade.

A análise não deve ser precipitada, a ocorrência de maiores intoxicações por suicídio é grave e deve ser tratada para além de uma situação casual ou acidente doméstico. Na Tabela 2, podemos identificar as principais circunstâncias de intoxicação em Goiás de 2005 a 2015.

Quanto à circunstância das notificações por intoxicação, a Tabela 3 apresenta a tentativa de suicídio como sendo a intoxicação com maior ocorrência (36,4\% das notificações - 1.086 casos), merecendo estudos futuros sobre este agravo em saúde uma vez que se deve ampliar a discussão, trazendo elementos sobre o modelo de atenção à saúde e a rede de atenção psicossocial nas quais o sujeito está inserido.

Não obstante, este resultado está atrelado a uma intoxicação crônica devido aos anos de exposição na aplicação de agrotóxicos, o que provoca problemas imunológicos, hematológicos, hepáticos, neurológicos, malformações congênitas, tumores, supõe-se que estes agravos à saúde podem acarretar sintomas depressivos, e com isso a ocorrência dos altos níveis das tentativas de suicídios.

Outro aspecto importante para se compreender a maior quantidade no número de suicídios relacionado à intoxicação por agrotóxico, diz respeito a transtornos psíquicos causados pela exposição a agrotóxicos, especialmente organofosforados, embora não sejam os únicos. Dentre estes transtornos estão a depressão e a ansiedade ${ }^{13,24}$.

Alguns estudos de caso realizados no Brasil indicam esta perspectiva. Parte destes estudos tece esta correlação de forma ainda preliminar, como é o caso do trabalho "Incidência de suicídios e uso de agrotóxicos por trabalhadores rurais em Luz/MG, Brasil”24.

Araújo et al..$^{13}$ ao realizarem um estudo sobre a exposição a agrotóxicos entre camponeses de Nova Friburgo/RJ identificaram uma relação direta entre este uso e distúrbios psiquiátricos.

Evidências científicas mostram que a exposição aos pesticidas pode levar a danos à saúde, muitas vezes irreversíveis, como o caso da neuropatia tardia por sobreexposição a organofosforados. As conseqüências neurotóxicas da exposição aguda por altas concentrações de pesticidas também estão bem estabelecidas, seja os efeitos muscarínicos, nicotínicos e no sistema nervoso central e periféri$c o^{13}(\mathrm{p} .116)$.

A pesquisa de Araújo et al. ${ }^{13}$ explica o porquê de tantas notificações por intoxicação relacionadas ao suicídio. A intoxicação crônica por anos de exposição a agrotóxicos, tanto de forma ocupacional como ambiental e pela sua ingestão (acidental) provoca danos severos a saúde mental e cardiovascular, acarretando em depressão do sujeito que não consegue mais trabalhar pelos danos cardiovasculares ou até mesmo pela própria depressão diretamente gerada pela intoxicação.

$\mathrm{Na}$ circunstância ocupacional das intoxicações foram 1.078 notificações $(36,1 \%$ das notificações), e como já fora tratado, estas intoxicações ocupacionais podem no futuro acarretar possíveis notificações por suicídio, visto que os trabalhadores intoxicados acabam com doenças crônicas.

Quanto a circunstância ocupacional e acidental, podemos destacar dois dados do Censo Agropecuário de $2006^{22}$, de que parte dos produtores rurais é analfabeta, se tratando do estado de Goiás, são 51\% de analfabetos. Não se pode considerar, a priori, que baixa escolaridade signifique pouco conhecimento: há extenso e fecundo saber popular e tradicional (saberes-fazeres) entre os diferentes grupos de trabalhadores do campo, mas não exatamente em relação aos agrotóxicos, produto da civilização ocidental urbano-industrial que necessita de assistência técnica e manejo adequado. 
Tabela 3. Circunstância da Intoxicação em Goiás (2005-2015).

\begin{tabular}{lccccc}
\hline \multirow{2}{*}{ Ano } & Acidental & Ocupacional & Suicídio & Homicídio & Alimentação \\
\cline { 2 - 6 } & Total em $\%$ & Total em $\%$ & Total em $\%$ & Total em \% & Total em \% \\
\hline 2005 & 22 & 31 & 44 & 0,6 & 1,6 \\
2006 & 29,2 & 22 & 47,8 & 0,3 & 0,3 \\
2007 & 26 & 32 & 41 & 0 & 1 \\
2008 & 35,2 & 29,1 & 33,6 & 0 & 2 \\
2009 & 31 & 26,7 & 41 & 0 & 1,1 \\
2010 & 28,8 & 35,7 & 33,6 & 0,3 & 0,4 \\
2011 & 14,6 & 50 & 34,2 & 0 & 0,7 \\
2012 & 25,6 & 39,1 & 33,5 & 1 & 3,5 \\
2013 & 31,4 & 33,4 & 31,1 & 0,6 & 0 \\
2014 & 14,9 & 54,6 & 30,1 & 0,3 & 0,4 \\
2015 & 25,2 & 41,6 & 32,7 & 0 & 1,2 \\
Total & 25,8 & 36,1 & 36,4 & 0,3 & \\
\hline
\end{tabular}

Fonte: CIT/ SUVISA (2016).

Outro dado importante é que a assistência técnica continua muito limitada, sendo praticada em apenas $22 \%$ dos estabelecimentos rurais - aqueles cuja área média é de 228 hectares. O Censo Agropecuário de $2006^{22}$ mostra que mais da metade dos estabelecimentos do Brasil onde houve utilização de agrotóxicos não recebeu orientação técnica (785 mil ou 56,3\%). O pulverizador costal, que é o equipamento de aplicação que apresenta maior potencial de exposição aos agrotóxicos, é o utilizado em 973 mil estabelecimentos. As embalagens vazias são queimadas ou enterradas em 358 mil estabelecimentos e 296 mil estabelecimentos não utilizaram nenhum equipamento de proteção individual. E nos estabelecimentos que utilizaram, a maioria adotou apenas botas e chapéu.

Analisando estes dados podemos entender algumas das observações nas fichas de notificação de intoxicação que relatam a intoxicação por consumirem refrigerante em recipiente que estava contaminado por agrotóxico, ou consumiu o agrotóxico ao se confundir com uma bebida qualquer.

Na Tabela 4 destaca-se os agrotóxicos que foram agentes de maior incidência de intoxicações. Em primeiro está o Roundup (Glifosato) com 725 casos, seguido do Furadan (Carbofuran), com 337 casos, o 2,4-D (Diclorofenociacético), com 116 casos, o Regent (Fenil-pirazol) com 64 casos, o Aldrin (Organoclorado) com 51 casos e o Furazin (Carbamato) com 34 casos.

Quanto aos efeitos clínicos que o intoxicado pode ter ao entrar em contato com algum des- tes agrotóxicos citados, temos desde irritação em mucosa até o desenvolvimento de câncer. Em pesquisa de Samsel e Seneff ${ }^{25}$ testes apontam que o glifosato, princípio ativo do Roundup, causará $50 \%$ do autismo em crianças até 2025 , e outras doenças modernas, como depressão, infertilidade, Alzheimer, câncer e doenças cardíacas.

Corroborando com estas previsões, o Guia de Prevenção, Notificação e Tratamento das Intoxicações por Agrotóxicos ${ }^{26}$ considera que os agrotóxicos com o princípio ativo Carbamato, como o Furazin e o Furadan (Carbofuran), podem provocar edema pulmonar, depressão, paralisia respiratória, perda de memória e até dificuldade motora nos intoxicados.

Já os inseticidas organoclorados, como o Aldrin, podem provocar vertigem, opacificação da córnea, insuficiência respiratória, atrofia testicular e consequente infertilidade e câncer. $\mathrm{E}$ os ácidos 2,4-Diclorofenociacético (2,4-D) causam desde irritação nos olhos e mucosas, até parada cardiorrespiratória. É importante ressaltar que o inseticida Aldrin foi proibido no Brasil desde 1985 , porém, como pode-se perceber, seu uso permanece.

\section{Desdobramentos das situações de exposição}

Quanto à evolução dos casos de intoxicação temos algumas nomenclaturas, como óbito, óbito por outra causa, cura (em que o intoxicado morreu proveniente de outra ocorrência, como assassinato ou suicídio), cura com sequela (em que o intoxicado adquiriu alguma sequela, como 
doença neurológica, pulmonar, etc). Quanto a evolução dos casos de intoxicação de Goiás podemos analisar a Tabela 5 .

Embora os óbitos de origem ocupacional representem uma pequena proporção, cada uma destas fatalidades carrega muita informação, uma vez que, atrás de cada óbito há vários trabalhadores convivendo nas mesmas condições, permanecendo expostos aos mesmos fatores de risco. Dessa forma, pode-se afirmar que "pouco significa muito"27, que uma vida perdida deve ser considerada e jamais desprezada.

Desta maneira, os casos de cura podem esconder quantidades alarmantes de intoxicados cronicamente que ao longo do tempo poderão

Tabela 4. Agrotóxicos que mais ocasionam notificações de intoxicações em Goiás (2005-2015)

\begin{tabular}{lcc}
\hline \multicolumn{1}{c}{ Agente tóxico } & $\begin{array}{c}\text { No de } \\
\text { notificações }\end{array}$ & Percentagem \\
\hline Roundup & 725 & $24,3 \%$ \\
Furadan & 337 & $11,3 \%$ \\
$2,4-D$ & 116 & $3,9 \%$ \\
Regent & 64 & $2,1 \%$ \\
Aldrin & 51 & $1,7 \%$ \\
Furazin & 34 & $1,1 \%$ \\
\hline
\end{tabular}

Fonte: CIT/ SUVISA (2016).

Tabela 5. Evolução do caso de intoxicações em Goiás (2005-2015).

\begin{tabular}{lrrrc}
\hline Ano & Óbito & Cura & $\begin{array}{c}\text { Cura } \\
\text { com } \\
\text { sequela }\end{array}$ & $\begin{array}{c}\text { Óbito } \\
\text { para } \\
\text { outra } \\
\text { causa }\end{array}$ \\
\hline 2005 & 16 & 286 & 16 & 0 \\
2006 & 16 & 231 & 20 & 0 \\
2007 & 9 & 164 & 14 & 1 \\
2008 & 6 & 234 & 7 & 0 \\
2009 & 20 & 230 & 8 & 0 \\
2010 & 13 & 262 & 16 & 0 \\
2011 & 9 & 205 & 4 & 1 \\
2012 & 4 & 286 & 2 & 0 \\
2013 & 3 & 339 & 3 & 0 \\
2014 & 8 & 322 & 6 & 0 \\
2015 & 9 & 215 & 2 & 0 \\
Total & 113 & 2774 & 98 & 2 \\
\hline Fonte: CIT/ SUVISA (2016). & & &
\end{tabular}

se manifestar, como cânceres, Alzheimer, infertilidade, doenças cardíacas, respiratórias. Assim, de qual cura estamos falando? Não obstante, de acordo com pesquisas contidas no "Dossiê ABRASCO. Um alerta sobre os impactos dos agrotóxicos na saúde. Parte 1 - Agrotóxicos, Segurança Alimentar e Saúde" ${ }^{\prime 28}$, estes efeitos crônicos podem ocorrer meses, anos ou até décadas após a exposição, manifestando-se em várias doenças como cânceres, malformação congênita, distúrbios endócrinos, neurológicos e mentais.

\section{Considerações finais}

O estudo apresentado levantou informações apresentadas nas Fichas de Intoxicação por agrotóxico do CIT-GO, sistematizando indicadores como período do ano com maiores intoxicações, idade mais atingida, evolução dos casos de intoxicação e municípios com maior incidência das intoxicações.

Nesta análise percebeu-se que deve-se considerar a proporção intoxicação por habitante para que sejam apresentados números reais ou mais próximos da realidade, dessa forma, nota-se uma alta incidência de intoxicações por agrotóxico na região de Goiânia (provavelmente pela quantidade de pessoas que habitam este município), Formosa (grande produtora de Soja) e a Mesorregião Sul Goiano, região territorializada pelo agronegócio, com o cultivo maciço da soja e do milho e com um avanço recente do agronegócio canavieiro.

A respeito do item presente nas fichas de notificações de intoxicações por agrotóxicos a respeito da "Evolução do caso", em que consta informações sobre óbito, cura, cura com sequela e óbito por outra causa, das 2.987 notificações 113 pessoas foram a óbito, 98 pessoas foram curadas com sequelas e 2.774 foram diagnosticadas por "cura". Contudo deve-se ressaltar que os efeitos crônicos (de longa duração) dos agrotóxicos não são registrados, como ressalta Bochner ${ }^{29}$, até mesmo por estes efeitos demorarem a se manifestar.

Deste modo, nota-se há a necessidade de ampliar o conhecimento sobre os efeitos crônicos à saúde da população expostas a estes produtos, pois pode haver um falso indicador a respeito do diagnóstico de cura da intoxicação que poderá se manifestar décadas depois. Enfim, deve-se questionar de qual cura se fala quando o assunto é prognóstico de melhora dos sintomas iniciais à intoxicação. 


\section{Colaboradores}

PDM Neves trabalhou na concepção, análise e interpretação de dados. MR Mendonça trabalhou na revisão crítica e redação do artigo. M Bellini trabalhou na análise e interpretação dos dados e revisão crítica. IB Pôssas trabalhou na elaboração cartográfica da pesquisa.

\section{Agradecimentos}

Agradecimento a Coordenação de Aperfeiçoamento de Pessoal de Nível Superior (CAPES) pelo apoio financeiro e concessão de bolsas.

\section{Referências}

1. Alves Filho JP. Uso de agrotóxicos no Brasil - controle social e interesses corporativos. São Paulo: Annablume, Fapesp; 2002.

2. Nunes MV, Tajara EH. Efeitos Tardios dos Praguicidas Organoclorados no Homem. Rev Saúde Pública 1998; 32(4):372-382.

3. Sobreira AEG, Adissi PJ. Agrotóxicos: Falsas Premissas e Debates. Cien Saude Colet 2003; 8(4):985-990.

4. Souza GS, Costa CAC, Maciel AC, Reis FDV, Pamplona YAP. Presença de agrotóxicos na atmosfera e risco à saúde humana: uma discussão para a Vigilância em Saúde Ambiental. Cien Saude Colet 2017; 22(10):3269-3280.

5. Neves PDM, Bellini M. Intoxicações por agrotóxicos na mesorregião norte central paranaense, Brasil - 2002 a 2011. Cien Saude Colet 2013; 18(11):31473156.

6. Espíndola MMM, Souza CDF. Trabalhador Rural: O agrotóxico e sua influência na saúde humana. Rev Uni Vale Rio Verde 2017; 15(2):871-880.

7. Silva AM, Alves SMF. Análise dos registros de intoxicação por agrotóxicos em Goiás, no período de 2001 a 2004. Rev Eletr Farmácia 2007; 4(2):194-201.

8. Ministério da Saúde (MS). Secretaria da Vigilância em Saúde. Agrotóxicos na ótica do Sistema Único de Saúde. Brasília: MS; 2016.

9. Agência Nacional de Vigilância Sanitária (ANVISA). A regulação e o mercado de agrotóxicos no Brasil. Brasília: ANVISA; 2012.

10. Arruda TF. Agrotóxicos e Sistema Penal [dissertação]. Maringá: Universidade Estadual de Maringá; 2008.

11. Nishiyama P. Utilização de agrotóxicos em áreas de reforma agrária no estado do Paraná. [tese]. Campinas: Universidade Estadual de Campinas; 2003.

12. Pignati WA, Machado JMH, Cabral JF. Acidente rural ampliado: o caso das "chuvas" de agrotóxicos sobre a cidade de Lucas do Rio Verde - MT. Cien Saude Colet 2007; 12(1):105-114.

13. Araújo AJ, Lima JS, Moreira JC, Jacob SC, Soares MO, Monteiro MCM, Amaral AM, Kubota A, Meyer A, Cosenza CAN, Neves CN, Markowitz S. Exposição múltipla a agrotóxicos e efeitos à saúde: estudo transversal em amostra de 102 trabalhadores rurais, Nova Friburgo, RJ. Cien Saude Colet 2007; 12(1):115-130.

14. Conselho Nacional de Secretários de Saúde (CONASS). Vigilância em saúde. Coleção Progestores - Para entender a gestão do SUS, 6, I. Brasília: CONASS; 2007.

15. Bombardi LM. Pequeno Ensaio Cartográfico sore o Uso de Agrotóxicos no Brasil. São Paulo: Laboratório de Geografia Agrária USP/Blurb (Ebook); 2016.

16. Bombardi LM. Geografia do Uso de Agrotóxicos no Brasil e Conexões com a União Europeia. São Paulo: FFLCH-USP; 2017.

17. Instituto Brasileiro de Geografia e Estatística (IBGE). Estimativas populacionais para municípios e para as Unidades da Federação brasileiras em 2015 [página na Internet]. Disponível em: http://www.ibge.gov.br/ home/estatistica/populacao/estimativa2015/estimativa_dou.shtm

18. Theisen G. O Mercado de agroquímicos [apresentação na Internet]. 2010. Disponível em: http://www.cnpsa. embrapa.br/met/images/arquivos/15MET/mercadoagroquimico.pdf 
19. Sindicato Nacional das Indústrias de Defensivos Agrícolas (SINDAG). Dados de produção e consumo de agrotóxicos [página na Internet]. 2011. Disponível em: www.sindag.com.br

20. Agência Internacional de Pesquisa em Câncer (IARC). Monographs on the Evaluation of Carcinogenic Risks to Humans [página na Internet]. 2010. Disponível em: http://monographs.iarc.fr/ENG/Classification/

21. Carneiro FF, Rigotto RM, Augusto LGS, Friedrich K, Búrigo AC, organizadores. Dossiê ABRASCO: um alerta sobre os impactos dos agrotóxicos na saúde. Rio de Janeiro: Escola Politécnica de Saúde Joaquim Venâncio/ FIOCRUZ; São Paulo: Expressão Popular; 2015.

22. Instituto Brasileiro de Geografia e Estatísticas (IBGE). Censo Agropecuário 2006. Brasília/Rio de Janeiro: IBGE; 2010.

23. Pignati WA, Oliveira NP, Silva AMC. Vigilância aos agrotóxicos: quantificação do uso e previsão de impactos na saúde-trabalho-ambiente para os municípios brasileiros. Cien Saude Colet 2014; 19(12):46694678.

24. Meyer TF, Resende IL, Abreu JC. Incidência de suicídios e uso de agrotóxicos por trabalhadores rurais em Luz (MG), Brasil. Rev Bras Saúde Ocup 2007; 32(116):24-30.

25. Samsel A, Seneff S. Glyphosate's Suppression of Cytochrome P450 Enzymes and Amino Acid Biosynthesis by the Gut Microbiome: Pathways to Modern Diseases. Entropy 2013; 15(4):1416-1463.

26. Mato Grosso do Sul. Centro Integrado de Vigilância Toxicológica - Centro Estadual de Referência em Saúde do trabalhador. Guia de prevenção, notificação e tratamento das intoxicações por agrotóxicos. Campo Grande: CIVITOX/CEREST; 2013.

27. Bochner R. Óbito ocupacional por exposição a agrotóxicos utilizado como evento sentinela: quando pouco significa muito. Vigil Sanit Debate 2015; 3(4):39-49.

28. Carneiro FF, Pignati WA, Rigotto, RM, Augusto LGS, Rizollo A, Muller N. Dossiê ABRASCO: Um alerta sobre os impactos dos agrotóxicos na saúde. Parte 1 Agrotóxicos, Segurança Alimentar e Saúde. Rio de Janeiro: ABRASCO; 2012.

29. Bochner R. Sistema Nacional de Informações TóxicoFarmacológicas - SINITOX e as intoxicações humanas por agrotóxicos no Brasil. Cien Saude Colet 2007; 12(1):73-89.

Artigo apresentado em 07/11/2017

Aprovado em 11/09/2018

Versão final apresentada em 13/09/2018 